\title{
Recherche et enseignement supérieur face à l'internationalisation. France, Suisse et Union européenne.
} Jean-Philippe Leresche, Philippe Larédo, Karl Weber (dir.), Presses polytechniques et universitaires romandes, Lausanne, 2009.

Denis Guthleben

\section{OpenEdition}

\section{Journals}

Édition électronique

URL : https://journals.openedition.org/histoire-cnrs/9253

DOI : 10.4000/histoire-cnrs.9253

ISSN : 1955-2408

\section{Éditeur}

CNRS Éditions

Édition imprimée

Date de publication : 15 octobre 2010

Pagination : 48

ISBN : 978-2-271-07114-9

ISSN : $1298-9800$

\section{Référence électronique}

Denis Guthleben, «Recherche et enseignement supérieur face à l'internationalisation. France, Suisse et Union européenne. ", La revue pour l'histoire du CNRS [En ligne], 25 | 2010, mis en ligne le 15 octobre 2010, consulté le 20 mai 2021. URL : http://journals.openedition.org/histoire-cnrs/9253 ; DOI : https:// doi.org/10.4000/histoire-cnrs.9253

Ce document a été généré automatiquement le 20 mai 2021

Comité pour l'histoire du CNRS 


\section{Recherche et enseignement supérieur face à}

\section{l'internationalisation. France, Suisse et Union européenne.}

Jean-Philippe Leresche, Philippe Larédo, Karl Weber (dir.), Presses

polytechniques et universitaires romandes, Lausanne, 2009.

\section{Denis Guthleben}

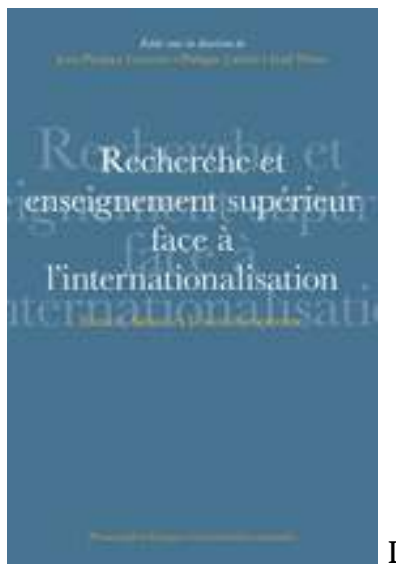

L'internationalisation de la recherche et de l'enseignement supérieur est devenue un lieu commun. Discours politiques et médiatiques, déclarations d'intention des acteurs de la science l'associent régulièrement à quelques généralités: la collaboration par-delà les frontières, le succès de programmes multilatéraux, l'ouverture des milieux scientifiques pour le meilleur, la fuite des cerveaux, la concurrence effrénée, l'immixtion d'obscurs intérêts privés pour le pire. Bref, un sujet clair, facile à circonscrire, aisé à définir.

1 Il suffit toutefois de se rapprocher de l'objet d'étude pour que, tel un mirage, il se déplace, se déforme ou s'estompe. Au fil de leurs articles, les quelque trente auteurs rassemblés par Jean-Philippe Leresche, Philippe Larédo et Karl Weber le rappellent 
bien : les grandes généralités ne résistent pas toujours à l'analyse plus fine de leurs déclinaisons nationales, régionales, voire locales. On s'en convainc à la lecture des cinq parties constituant cet excellent ouvrage, qui s'annonce modestement comme une étude des cas français et suisse, mais qui en réalité voit beaucoup plus large et n'est pas avare de comparaisons intra- et extra-européennes.

2 La première partie, consacrée au rôle de l'internationalisation dans la construction et les évolutions des systèmes de recherche et d'enseignement supérieur, montre que ce processus évolue et fait constamment évoluer autour de lui les instances, les règles et les pratiques, en stimulant par exemple l'émergence de nouveaux types d'échanges électroniques analysés par Olivier Glassey. La deuxième partie est dédiée à la mesure de l'internationalisation, aux indicateurs qui permettent de l'atteindre, ainsi qu'à ses enjeux et à ses conséquences. Grâce à Karl Weber et à Thérèse Zimmermann, on y découvre entre autres - entre beaucoup d'autres... - de profondes différences entre les disciplines (avec le retard des sciences humaines et sociales, toujours démoralisant pour les chercheurs de ces disciplines), mais aussi au sein d'une même discipline entre les discours et leur mise en pratique. Les troisième et quatrième parties mettent l'accent sur deux mécanismes observables de l'internationalisation, allant de l'international vers le national, avec la diffusion et, le cas échéant, l'appropriation ou le rejet des recettes, des pratiques, des politiques mises en avant aux niveaux international et européen, ou avec l'application par certains pays comme la France du point de vue de la gouvernance de la recherche et de l'innovation pour Jean-Alain Héraud, de logiques multi-niveaux. Enfin, la cinquième partie aborde les tensions qui peuvent exister, dans ce contexte, entre d'une part des échanges scientifiques qui accélèrent et se multiplient, et, d'autre part, la nécessité, notamment dans l'optique d'innovation industrielle étudiée par Beat Hotz-Hart, d'établir des dispositifs de protection qui ne viennent pas freiner la dynamique d'ouverture et amoindrir ses effets vertueux.

En somme, voici un ouvrage extrêmement riche, dont on ressort conforté dans certaines convictions, ébranlé dans d'autres et, au final, avec une certitude: l'internationalisation de la recherche n'est pas un phénomène simple dont on pourrait résumer en quelques mots les mécanismes et les conséquences ; mais elle n'est pas non plus un dédalle entortillé, à condition de vouloir, comme les auteurs ici réunis s'en sont donné les moyens, analyser les bonnes variables. En tout cas, ceux que le labyrinthe de l'internationalisation inquiète encore ont trouvé là un guide.

\section{AUTEUR}

\section{DENIS GUTHLEBEN}

Historien, attaché scientifique au Comité pour l'histoire du CNRS. 